\title{
Analisis Kinerja Algoritma Support Vector Machine (SVM) Guna Pengambilan Keputusan Beli/Jual Pada Saham PT Elnusa Tbk. (ELSA)
}

\author{
Elfa Aufa Nida ${ }^{1}$, Agung Budi Prasetijo ${ }^{2}$, Risma Septiana ${ }^{3}$ \\ ${ }^{1}$ Departemen Teknik Komputer, Fakultas Teknik, Universitas Diponegoro \\ ${ }^{2}$ Departemen Teknik Komputer, Fakultas Teknik, Universitas Diponegoro \\ Jl. Prof. Soedarto Tembalang Semarang 50275, (024-76480609, email : \\ agungprasetijo@ce.undip.ac.id \\ 3Departemen Teknik Komputer, Fakultas Teknik, Universitas Diponegoro \\ Jl. Prof. Soedarto Tembalang Semarang 50275, (024)-76480609, email : \\ rismaseptiana@live.undip.ac.id
}

Jl. Prof. Soedarto Tembalang Semarang 50275, (024)-76480609, email : elfaaufan@gmail.com

\section{ARTICLE INFO}

Article history:

Received 11 October 2019

Received in revised form 02 January 2020

Accepted 02 January 2020

Available online 31 January 2020

\begin{abstract}
Stock is one of investing method that can improve the economy. Remote trading is one of the most popular trading method. Remote trading requires prediction of stock transaction signals to make it easier for traders to make decisions. Technical analysis is made easy with various indicators in analyzing stock price chart movements, such as Bollinger Bands, Pivot Point, MACD, Stochastic, ADX, and CCI, and then combined with Support Vector Machine (SVM) algorithm to classify sell/buy/hold classes, so we can obtain a pattern that is useful for predicting stock transaction signal decisions. The study was using WEKA software by analyzing the combination of indicators with the SVM algorithm where the object is historical data stocks of PT Elnusa Tbk. (ELSA). The highest profit obtained from this study is $28,02 \%$ which is the best model of the results of the data that is trained using non-aggressive sub sectors data using exponent value 2.

Keywords: Stocks, Technical Analysis, SVM, WEKA
\end{abstract}

\section{Pendahuluan}

Analisis dibutuhkan oleh seorang trader sebelum melakukan kegiatan beli/jual saham. Analisis yang biasa digunakan oleh seorang trader adalah analisis teknikal. Analisis teknikal merupakan sebuah metode untuk memprediksi pergerakan harga (saham, forex, komoditas, dsb) dengan menggunakan grafik, atau data harga historis dari masa lampau [1]. Analisis teknikal dipermudah oleh berbagai indikator dalam menganalisis grafik pergerakan harga saham. Indikator yang digunakan pada penelitian ini antara lain indikator Bollinger Bands yang terdiri dari 3 buah garis yaitu garis batas atas (upper bands), batas bawah (lower bands), dan garis tengah (middle bands) yang diperoleh dari perhitungan Simple Moving Average (SMA). Indikator Pivot Point yang terdiri dari 5 garis, yaitu nilai pivot points, support \#1, support \#2, Resistance \#1, dan Resistance \#2 yang dihitung dengan menggunakan open, high, low, dan close dari sesi trading terakhir, yakni Received October 11, 2019; Revised January 02, 2019; Accepted January 02, 2019 
pada sesi II hari sebelumnya. Indikator Moving Average Convergence Divergence (MACD) memiliki 3 bagian indikator, yakni garis MACD, garis sinyal, dan histogram. Indikator Stochastic mempunyai 2 garis yang disebut dengan garis $\% \mathrm{~K}$ dan garis $\% \mathrm{D}$, garis $\% \mathrm{~K}$ mempunyai periode yang lebih panjang daripada garis \%D. Indikator Average Directional Index Movement (ADX) terdapat 3 buah garis, yakni garis ADX bersama 2 buah garis Directional Movement Index (DMI) atau biasa disebut juga garis +DI dan garis -DI. Indikator Commodity Channel Index $(\mathrm{CCl})$ memiliki 2 garis yaitu garis $\mathrm{CCl}$ dan garis Moving Average.

Machine learning merupakan suatu cabang dari ilmu kecerdasan buatan dimana berbagai probabilistik, statistik, dan alat optimasi digunakan yang mana diambil dari contoh-contoh data yang lalu atau telah ada dan kemudian melalui pelatihan (training) yang digunakan untuk mengklasifikasi data baru atau untuk mengidentifikasi pola baru [2]. Penelitian ini menggunakan metode Knowledge Discovery in Database (KDD) untuk memperoleh pengetahuan dari database yang ada. Di dalam KDD terdapat lima tahap yaitu, data selection, preprocessing/cleaning, data transformation, data mining, dan interpretation/evalution.

Perangkat lunak yang digunakan dalam penelitian ini adalah WEKA (Waikato Environment for Knowledge Analysis) yang berfungsi untuk membantu trader dalam menentukan prediksi sinyal keputusan beli/jual saham dengan menggunakan berbagai algoritma yang ada di dalamnya, salah satunya adalah algoritma Support Vector Machine (SVM) yang digunakan dalam penelitian ini.

Algoritma Support Vector Machine (SVM) merupakan suatu teknik untuk menemukan hyperplane yang bisa memisahkan dua set data dari dua kelas yang berbeda [3]. Prinsip dasar SVM adalah linear classifier dan selanjutnya dikembangkan agar dapat bekerja pada masalah nonlinear dengan memasukkan konsep kernel trick pada ruang kerja berdimensi tinggi. Salah satu jenis kernel yang banyak digunakan ada polynomial kernel. Saham yang dipilih pada penelitian ini adalah saham dari PT Elnusa Tbk (Kode saham: ELSA).

Penelitian terdahulu yang digunakan pada penelitian ini antara lain penelitian Reza Fahlevi Panggabean (2018) yang bertujuan untuk merancang sistem serta melakukan analisis menggabungkan indikator Bollinger Bands dan William Percent Range untuk memberikan masukan kepada user sebagai sinyal jual atau beli [4]. Penelitian Tegar Widya Pranata (2018) yang bertujuan untuk merancang sistem serta melakukan analisis menggabungkan indikator Bollinger Bands dan Moving Avarage Convergence Divergence (MACD) untuk memberikan masukan kepada user sebagai sinyal jual atau beli [5]. Penelitian Mutmainah, dkk (2017) yang bertujuan untuk menguji keakuratan analisis teknikal indikator Stochastic Oscillator dalam menentukan sinyal beli dan jual pada saham yang tergabung dalam sub sektor konstruksi dan bangunan periode 20142016 [6]. Penelitian Sarbajit Paul (2016) yang bertujuan untuk membuktikan keakuratan dari indikator ADX pada saham Nifty dan menghitung posisi keuntungannya dengan periode 13 hari Moving Average [7]. Penelitian Andri Supriadi (2014) yang bertujuan untuk mengetahui probabilitas profit dari sinyal jual dan sinyal beli yang dihasilkan indikator Stochastic Oscillator, Money Flow Indeks (MFI), Commoditi Channel Index (CCl) dan Chaikin Money Flow Index (CMF) perdagangan foreign exchange pada pasangan mata uang Euro terhadap Dolar Amerika (EURUSD) [8]. Penelitian Pusphita Anna Octaviani, dkk (2014) yang bertujuan menerapkan metode klasifikasi SVM pada data akreditasi sekolah dasar di Magelang [9]. Penelitian Arif Pratama, dkk (2018) yang bertujuan untuk dapat mengklasifikasikan data prediksi kelulusan mahasiswa secara tepat berdasarkan parameter-parameter yang telah ditentukan [10].

Kajian penelitian-penelitian terdahulu diatas menjadi referensi dalam proses penelitian pengambilan keputusan untuk beli atau jual dengan mengkombinasikan indikator Bollinger Bands, Pivot Point, Moving Average Convergence Divergence (MACD), Stochastic, ADX, dan CCI, dengan algoritma Support Vector Machine (SVM) dimana objek yang diteliti adalah saham dari PT Elnusa Tbk (ELSA).

\section{Metode Penelitian}

Metodologi penelitian yang digunakan pada penelitian ini adalah metode Knowledge Discovery in Database (KDD). Metode ini memiliki lima tahap penelitian.

\subsection{Data Selection}

Data penelitian yang digunakan pada penelitian ini adalah data harga saham dari PT Elnusa Tbk (ELSA) selama 2,5 tahun terhitung dari 1 Juli 2016 hingga 31 Desember 2018 yang didapatkan dari situs Yahoo Finance. Data yang didapatkan memiliki fomat .csv sehingga untuk dapat mengolah data tersebut harus diubah ke dalam format .xlsx. 
Pengumpulan data dari sub sektor saham juga dibutuhkan dalam penelitian ini. Data tersebut adalah data saham dari perusahaan lain yang berada di sub sektor yang sama, yaitu PT Medco Energi Internasional Tbk. (MEDC) dan PT Surya Esa Perkasa Tbk. (ESSA).

2.2 Data Preprocessing

Pada proses ini ditambahkan variabel atribut yang mendukung dalam pengolahan data penelitian ini yaitu beberapa perhitungan indikator seperti Bollinger Band, Pivot Point, MACD, Stochastic, ADX, dan CCI.

Setelah dilakukan perhitungan, kedua data ditambahkan kelas yang berisi sinyal beli/jual/tahan yang ditentukan secara manual dengan membaca grafik harga saham, sebelumnya kedua data tersebut dibagi lagi menjadi masing-masing dua tipe investor yaitu non-agresif dan agresif. Penentuan kelas dibantu dengan indikator Bollinger Band, MACD, dan Stochastic.

a. Non-agresif

Cara menentukan sinyal beli/jual pada tipe ini dengan melihat indikator Bollinger Band yaitu apabila akan memutuskan beli maka dilakukan ketika sedang downtrend dan sudah melewati garis batas bawah. Apabila akan memutuskan sinyal jual maka dilakukan ketika sedang uptrend dan sudah melewati garis batas atas.

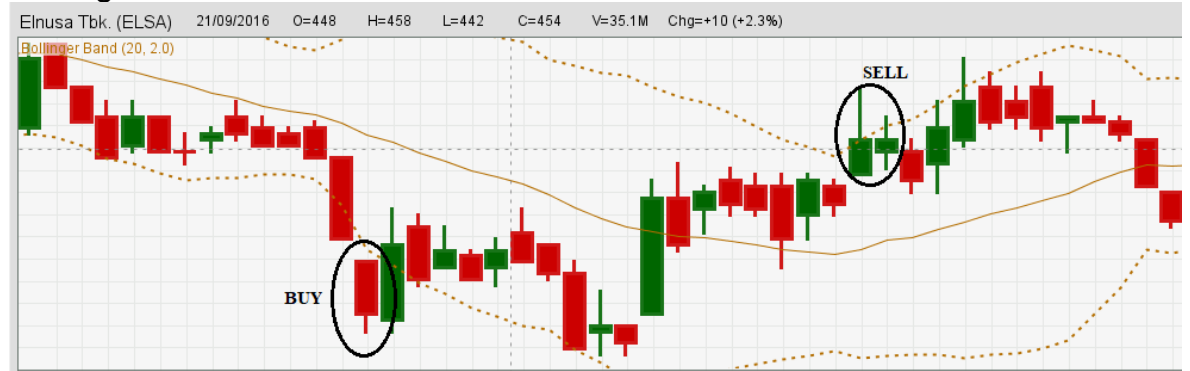

b. Agresif

Gambar 1 Penentuan sinyal jual/beli data non-agresif

Cara menentukan sinyal beli/jual dengan indikator Bollinger Band pada tipe ini sama seperti yang dilakukan pada tipe non-agresif. Selanjutnya untuk menentukan keputusan beli/jual dengan indikator MACD yaitu dengan melihat perpotongan antar dua garis, garis MACD dan garis sinyal. Keputusan beli diambil ketika garis MACD memotong garis sinyal dari arah bawah ke atas, sedangkan keputusan jual diambil ketika garis MACD memotong garis sinyal dari arah atas ke bawah. Kemudian untuk indikator Stochastic, keputusan beli diambil ketika garis \%K dan garis \%D saling berpotongan dibawah $20 \%$ batas bawah dan keputusan jual diambil ketika garis \%K dan \%D saling berpotongan diatas $80 \%$ batas atas.

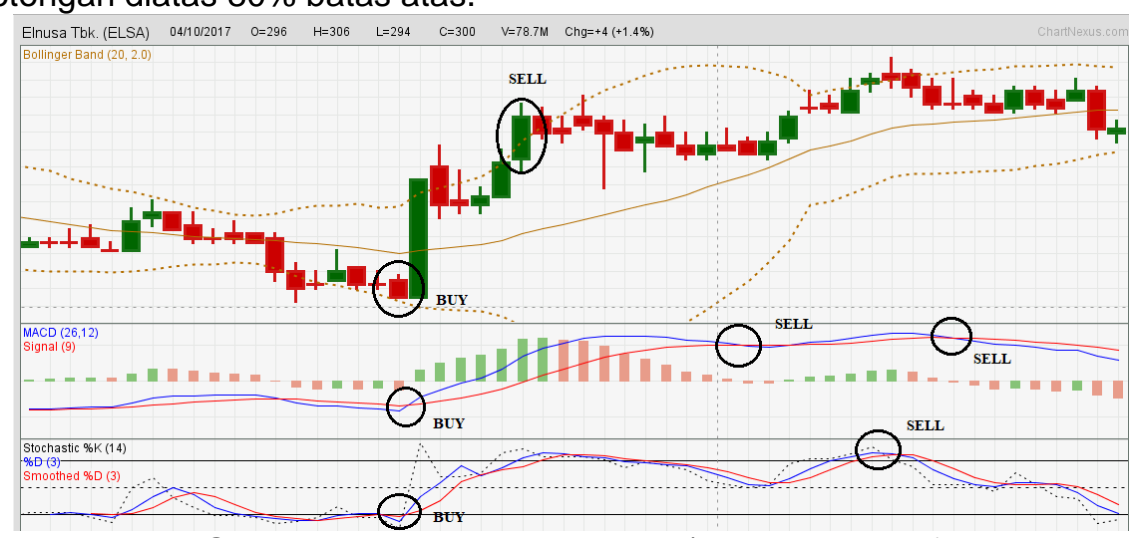

Data Transformation

Gambar 2 Penentual sinyal jual/beli data agresif

Data latih yang sudah ditambahkan dengan keputusan jual/beli kemudian di simpan ke dalam format .csv agar data dapat dibaca oleh tools WEKA. Kemudian agar data dapat diolah pada tools WEKA maka data tersebut harus disimpan ke dalam format .arff. Di dalam weka terdapat tools ARFF-Viewer yang mana dapat membaca dokumen dengan format .csv. Setelah dibuka pada ARFF-Viewer, selanjutnya menyimpan data latih tersebut dengan format .arff agar siap untuk diolah pada proses selanjutnya.

TRANSFORMATIKA Vol. 17, No. 2, January $2020: 179-189$ 


\section{$2.4 \quad$ Data Mining}

Proses selanjutnya adalah melakukan pelatihan data latih ke dalam WEKA dengan algoritma Support Vector Machine (SVM) yang nantinya akan menghasilkan suatu pola atau informasi yang dapat disimpan dan digunakan pada saat melakukan pengujian pada data tes. Pada proses pelatihan data dalam WEKA ini terdapat beberapa tahapan, diantaranya sebagai berikut: a.

\section{Preprocessing}

Tahap ini merupakan tahap pembersihan pada data latih, yaitu penghapusan atribut yang tidak dibutuhkan saat proses klasifikasi. Penghapusan ini bertujuan agar atribut yang tidak dibutuhkan tersebut tidak mempengaruhi proses dan hasil klasifikasi. Ada 21 atribut yang dipakai pada proses ini yaitu BB atas, BB tengah, BB Bawah, PP, R1, R2, R3, S1, S2, S3, MACD, Signal, Fast \%K, Slow\%D, Smoothed \%D, +DI14, -DI14, ADX, CCI, MA, CLASS.

b. Klasifikasi

Proses ini merupakan proses pemilihan classifier yang gunanya untuk pembentukan pola atau informasi dari data latih. Classifier yang digunakan adalah Sequential Minimal Optimization (SMO). Classifier SMO bekerja dengan cara membagi dua kelas untuk mencari hyperplane terbaik dari banyaknya kemungkinan. Hyperplane terbaik didapatkan dengan memaksimalkan margin atau jarak antar dua set objek dari kelas yang berbeda.

Classifier Sequential Minimal Optimization (SMO) memiliki beberapa parameter yang memiliki nilai awal masing-masing yang sudah ditetapkan oleh tools WEKA. Pada parameter classifier SMO terdapat tipe filter yang digunakan, tipe filter yang digunakan pada pelatihan ini adalah normalisasi sehingga nilai dari perhitungan indikator akan bernilai antara 0 hingga 1.

Kernel juga merupakan salah satu parameter yang digunakan pada classifier SMO. Data yang digunakan merupakan data non-linier yang memiliki banyak atribut, sehingga untuk proses klasifikasinya data harus dipetakan dan dipisahkan menjadi data linier pada ruang kerja berdimensi tinggi dengan menggunakan fungsi kernel.

Kernel yang digunakan pada classifier SMO yaitu Polynomial Kernel yang merupakan default parameter yang diberikan oleh tools WEKA dan kernel ini sangat cocok digunakan pada data yang dinormalisasi. Di dalam Polynomial Kernel terdapat beberapa parameter, salah satunya yaitu nilai eksponen. Nilai eksponen akan mempengaruhi hasil akhir dari hyperplane. Gambar 3 menunjukkan parameter yang ada pada Polynomial Kernel.

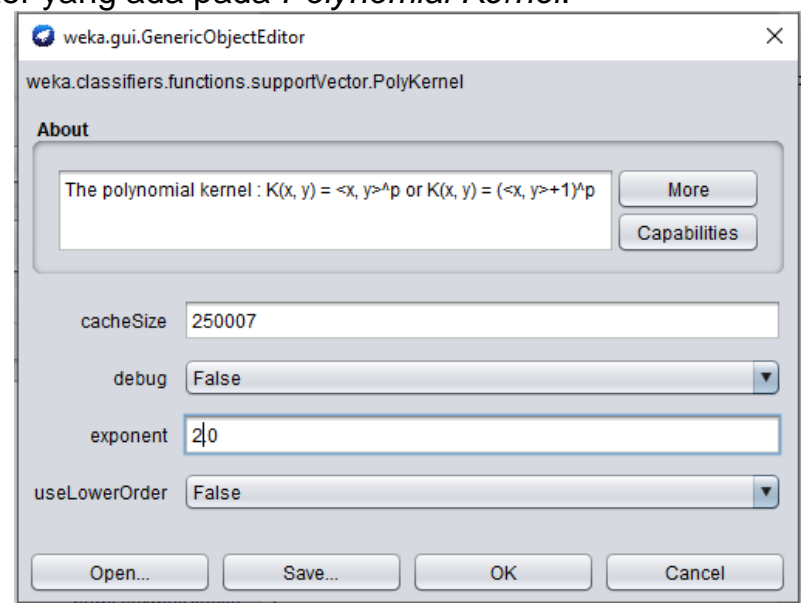

Gambar 3 Perubahan eksponen

Pada penelitian ini untuk mencari hasil akurasi yang maksimal dilakukan uji coba dengan mengubah nilai eksponen dengan nilai 2.0 hingga 3.0. Eksponen yang bernilai awal 1.0 diubah menjadi 2.0 dikarenakan nilai eksponen 1.0 hanya digunakan untuk data linier. Polynomial Kernel dinotasikan menjadi persamaan.

$$
K(x, y)=(<x, y>+1)^{P}
$$

Nilai $\mathrm{p}$ merupakan nilai eksponen yang diubah pada penelitian ini. Nilai eksponen berpengaruh terhadap linieritas dari hyperplane. Semakin kecil nilai eksponen maka hyperplane semakin linier.

Setelah hyperplane ditemukan, maka akan didapatkan titik-titik support vector dari kedua kelas. Titik-titik support vector tersebut selanjutnya akan dimasukkan dan dijumlahkan ke dalam persamaan $2[10]$.

$$
f(x)=\sum_{i=1}^{n} \alpha_{i} y_{i} K\left(x_{i}, x\right)+b
$$


Pada persamaan $2 \mathrm{n}$ merupakan jumlah support vector, $\mathrm{K}(\mathrm{xi}, \mathrm{x})$ adalah fungsi kernel, dan $b$ adalah nilai bias. Hasil dari perhitungan tersebut akan menampilkan akurasi dari proses pelatihan data latih.

\subsection{Interpretation/Evaluation}

Data tes yang sudah terdapat perhitungan indikator dan kelas kemudian disimpan ke dalam format .csv dan diubah ke dalam format .arff menggunakan tools ARFF-Viewer. Pengujian dimulai ketika data tes sudah dimasukkan ke dalam tools WEKA. Hasil pengujian akan menampilkan prediksi keputusan beli/jual/tahan yang diberikan oleh tools WEKA dan persentase kesesuaian antara kelas yang sudah diberikan secara manual dengan prediksi kelas yang diberikan oleh tools WEKA.

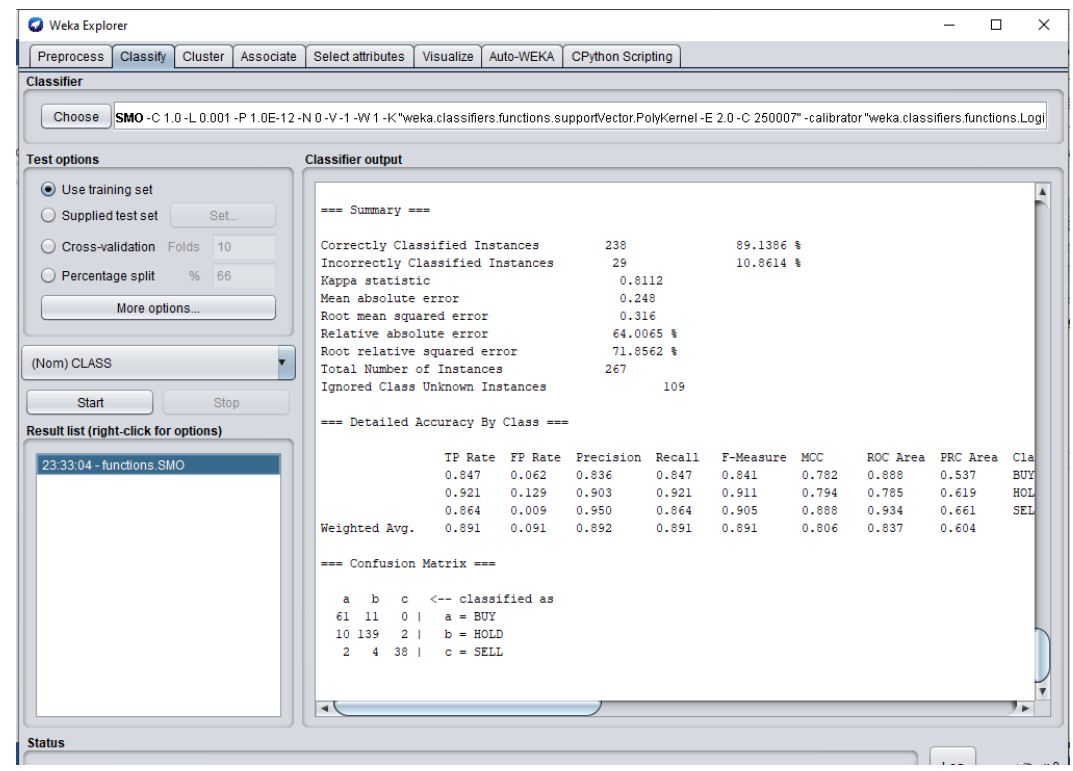

Gambar 4 Hasil Prediksi

Gambar 4 menampilkan hasil dari proses prediksi dari data tes selama 1 tahun. Di dalamnya juga ditampilkan aktual kelas, sehingga memudahkan untuk mencari perbedaan sinyal beli/jual/tahan yang diubah oleh prediksi dari tools WEKA.

a. Pengukuran Kinerja

Pengukuran kinerja pada penilitian ini terdiri dari dua macam yaitu perbandingan akurasi dan perhitungan keuntungan. Perbandingan akurasi dilakukan untuk menganalisa kinerja dari algoritma.

Perhitungan keuntungan dilakukan untuk menghitung keuntungan dari proses beli/jual saham selama 1 tahun berdasarkan sinyal beli/jual yang dihasilkan dari hasil prediksi. Perhitungan dimulai dari sinyal beli pertama yang muncul selama periode tersebut. Berikut tiga perhitungan yang digunakan untuk mengukur keuntungan yang dihasilkan selama 1 tahun dari hasil prediksi sinyal beli/jual saham yang dihasilkan.

1. Sinyal Beli

Pada saat sinyal beli muncul maka diasumsikan untuk membeli saham dengan nilai modal awal adalah Rp 100.000. Perhitungan pada kondisi sinyal beli dapat menggunakan persamaan 3.

2. Sinyal Jual

$$
\text { Sinyal Beli }=\frac{\text { Modal }}{\text { Close }}
$$

Pada saat sinyal jual maka diasumsikan untuk menjual saham yang dimiliki. Perhitungan pada kondisi sinyal jual dapat menggunakan persamaan 4.

3. Persentase Keuntungan

$$
\text { Sinyal Jual }=\text { Asset } \times \text { Close }
$$

Perhitungan persentase keuntungan bermaksud untuk menghitung berapa persen keuntungan yang didapatkan dari beli/jual selama satu tahun. Perhitungan persentase keuntungan dapat menggunakan persamaan 5 .

$$
\% \text { Keuntungan }=\frac{\text { Uang-Modal }}{\text { Modal }} \times 100 \%
$$

TRANSFORMATIKA Vol. 17, No. 2, January 2020: 179-189 


\section{Hasil dan Analisa}

\subsection{Pemodelan Data SVM}

Pada penelitian ini akan dihasilkan pemodelan data dari algoritma SVM dari proses pelatihan dan pengujian yang dilakukan terhadap empat macam data. Keempat data tersebut dilatih dan diuji sebanyak dua kali menggunakan algoritma SVM dengan perbedaan pada nilai eksponen yang terdapat pada Polynomial Kernel. Nilai eksponen yang digunakan yaitu 2 dan 3.

1. Data Non-agresif Saham PT Elnusa Tbk. (ELSA)

a. $\quad$ Pelatihan dan pengujian saat nilai eksponen 2

Pada proses pelatihan menggunakan classifier SMO data dibagi menjadi tiga pemodelan, yang pertama yaitu kelas hold dan buy, kedua kelas hold dan sell, ketiga kelas buy dan sell. Hal ini dikarenakan classifier SMO merupakan binary classifier yang bekerja mengklasifikasikan terhadap dua kelas data. Proses pemodelan menghasilkan titik-titik support vector yang merupakan pattern terdekat dengan lokasi hyperplane.

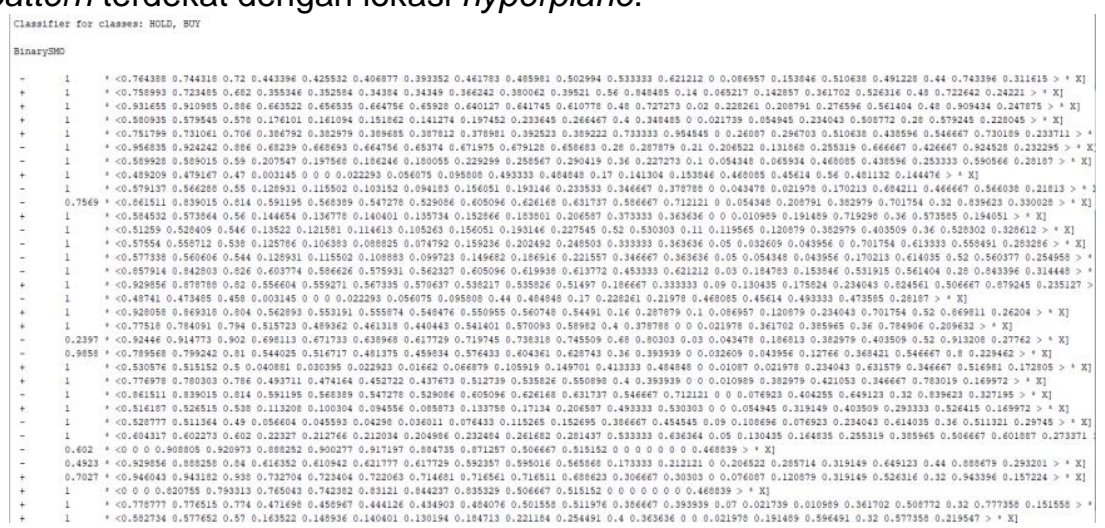

Gambar 1 Pemodelan hold-buy data non-agresif saham ELSA (2)

Gambar 5 menunjukkan pemodelan hold dan buy pada data non-agresif saham ELSA dengan nilai eksponen 2 yang didalamnya terdapat 40 titik support vector.

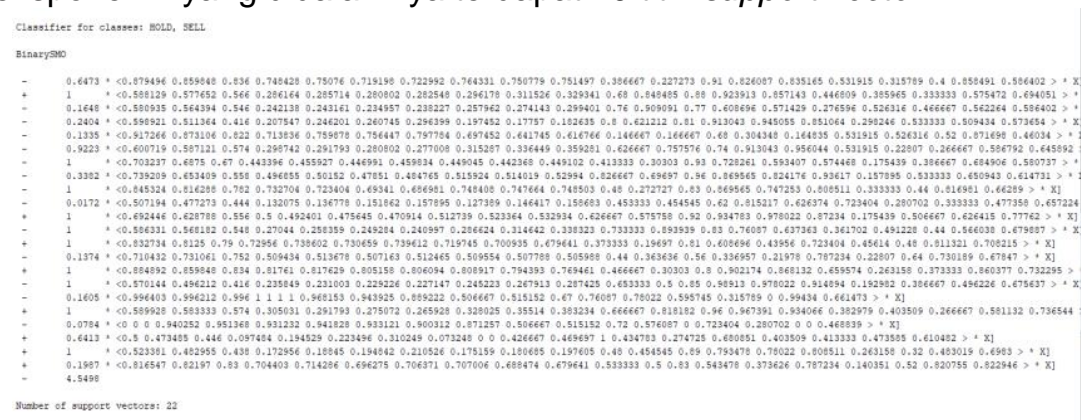

Gambar 2 Pemodelan hold-sell data non-agresif saham ELSA (2)

Gambar 6 menunjukkan pemodelan hold dan sell pada data non-agresif saham ELSA dengan nilai eksponen 2 yang didalamnya terdapat 22 titik support vector.

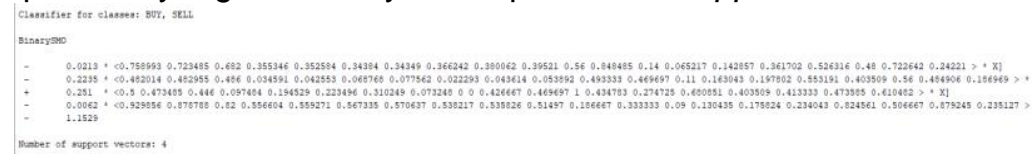

Gambar 3 Pemodelan buy-sell data non-agresif saham ELSA (2)

Gambar 7 menunjukkan pemodelan buy dan sell pada data non-agresif saham ELSA dengan nilai eksponen 2 yang didalamnya terdapat 4 titik support vector.

b. Pelatihan dan pengujian saat nilai eksponen 3

Pada proses pelatihan untuk data non-agresif saham ELSA dengan menggunakan nilai eksponen 3 juga dihasilkan tiga pemodelan, yaitu:

- Pemodelan hold dan buy didapatkan 26 titik support vector

- Pemodelan hold dan sell didapatkan 15 titik support vector

- Pemodelan buy dan sell didapatkan 4 titik support vector

2. Data Agresif Saham PT Elnusa Tbk. (ELSA) 
a. $\quad$ Pelatihan dan pengujian saat nilai eksponen 2

Pada proses pelatihan untuk data agresif saham ELSA dengan menggunakan nilai eksponen 2 juga dihasilkan tiga pemodelan, yaitu:

- Pemodelan hold dan sell didapatkan 34 titik support vector

- Pemodelan hold dan buy didapatkan 69 titik support vector

- Pemodelan sell dan buy didapatkan 7 titik support vector

b. Pelatihan dan pengujian saat nilai eksponen 3

Pada proses pelatihan untuk data agresif saham ELSA dengan menggunakan nilai eksponen 3 juga dihasilkan tiga pemodelan, yaitu:

- Pemodelan hold dan sell didapatkan 28 titik support vector

- Pemodelan hold dan buy didapatkan 59 titik support vector

- Pemodelan sell dan buy didapatkan 6 titik support vector

3. Data Non-agresif Saham Sub Sektor

a. $\quad$ Pelatihan dan pengujian saat nilai eksponen 2

Pada proses pelatihan untuk data non-agresif saham sub sektor dengan menggunakan nilai eksponen 2 juga dihasilkan tiga pemodelan, yaitu:

- Pemodelan hold dan buy didapatkan 115 titik support vector

- Pemodelan hold dan sell didapatkan 85 titik support vector

- Pemodelan buy dan sell didapatkan 12 titik support vector

b. Pelatihan dan pengujian saat nilai eksponen 3

Pada proses pelatihan untuk data non-agresif saham sub sektor dengan menggunakan

nilai eksponen 3 juga dihasilkan tiga pemodelan, yaitu:

- Pemodelan hold dan buy didapatkan 93 titik support vector

- Pemodelan hold dan sell didapatkan 62 titik support vector

- Pemodelan buy dan sell didapatkan 10 titik support vector

4. Data Agresif Saham Sub Sektor

a. $\quad$ Pelatihan dan pengujian saat nilai eksponen 2

Pada proses pelatihan untuk data agresif saham sub sektor dengan menggunakan nilai eksponen 2 juga dihasilkan tiga pemodelan, yaitu:

- Pemodelan hold dan sell didapatkan 114 titik support vector

- Pemodelan hold dan buy didapatkan 225 titik support vector

- Pemodelan sell dan buy didapatkan 18 titik support vector

b. Pelatihan dan pengujian saat nilai eksponen 3

Pada proses pelatihan untuk data agresif saham sub sektor dengan menggunakan nilai eksponen 3 juga dihasilkan tiga pemodelan, yaitu:

- Pemodelan hold dan sell didapatkan 118 titik support vector

- Pemodelan hold dan buy didapatkan 191 titik support vector

- Pemodelan sell dan buy didapatkan 15 titik support vector

3.2 Perbandingan Akurasi

Persentase yang dihasilkan dari proses pelatihan dan pengujian pada keempat data didapat dari hasil confusion matrix setiap prosesnya, lalu persentase tersebut dapat divisualisasikan dengan menggunakan grafik, sehingga dapat dilihat perbandingan persentase dari proses pelatihan dan pengujian pada setiap data.

TRANSFORMATIKA Vol. 17, No. 2, January 2020: 179-189 


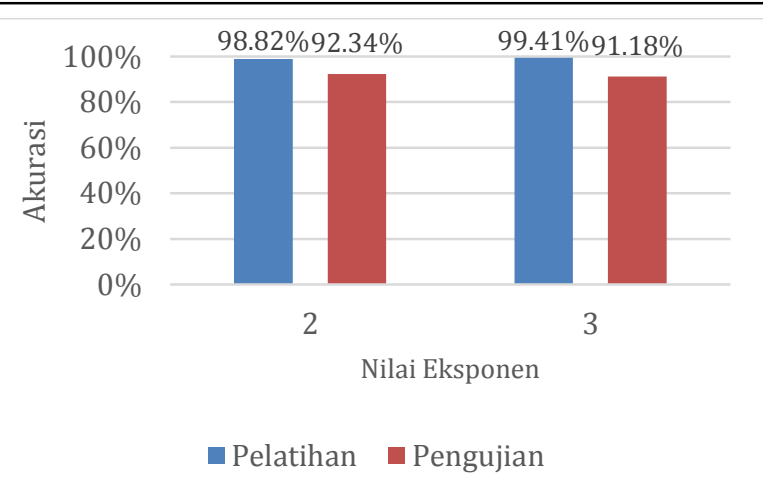

Gambar 4 Grafik akurasi data non-agresif saham ELSA

Gambar 8 menunjukkan perbandingan persentase hasil pelatihan dan hasil pengujian dari data non-agresif saham PT Elnusa Tbk. (ELSA). Data diuji dan dilatih menggunakan nilai eksponen yang berbeda yang mana akan menghasilkan persentase hasil pelatihan dan pengujian yang berbeda pula. Pada saat nilai eksponen 2 persentase hasil pelatihan dan pengujian sebesar $98,82 \%$ dan $92,34 \%$, kemudian saat nilai eksponen 3 persentase hasil pelatihan dan pengujian sebesar $99,41 \%$ dan $91,19 \%$.

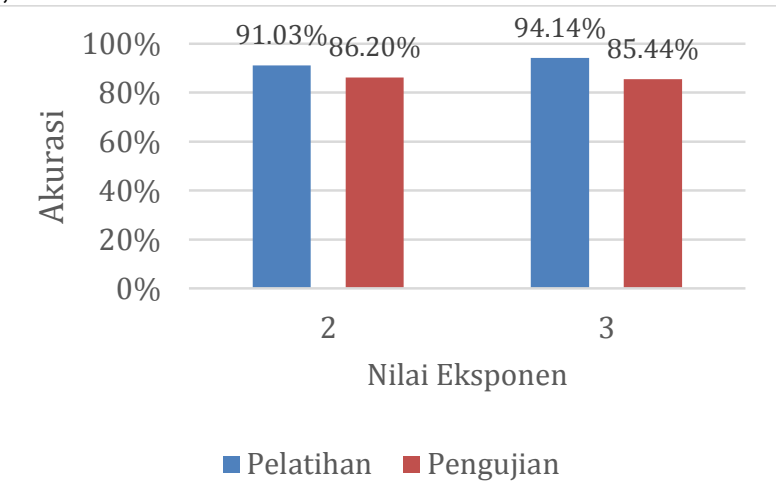

Gambar 5 Grafik akurasi data agresif saham ELSA

Gambar 9 menunjukkan perbandingan persentase hasil pelatihan dan pengujian pada data agresif saham PT Elnusa Tbk. (ELSA). Sama halnya yang dilakukan pada data non-agresif, data ini juga dilatih dan diuji dengan nilai eksponen pada kernel yang berbeda. Persentase hasil pelatihan dan pengujian saat nilai eksponen 2 sebesar $91,03 \%$ dan $86,20 \%$, sedangkan saat nilai eksponen 3 persentase hasil pelatihan dan pengujian sebesar $94,14 \%$ dan $85,44 \%$.

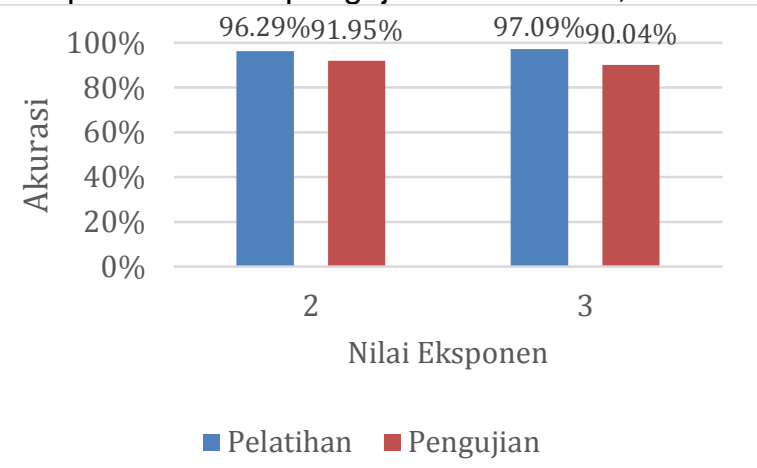

Gambar 6 Grafik akurasi data non-agresif saham sub sektor

Gambar 10 menunjukkan perbandingan persentase hasil pelatihan dan hasil pengujian pada data non-agresif saham sub sektor. Sama halnya dengan data saham, data sub sektor juga diuji dan dilatih menggunakan nilai eksponen yang berbeda. Persentase hasil pelatihan dan pengujian pada saat nilai eksponen 2 sebesar $96,29 \%$ dan $92,34 \%$, sedangkan saat nilai eksponen 3 persentase hasil pelatihan dan pengujian sebesar $97,09 \%$ dan $90,04 \%$. 


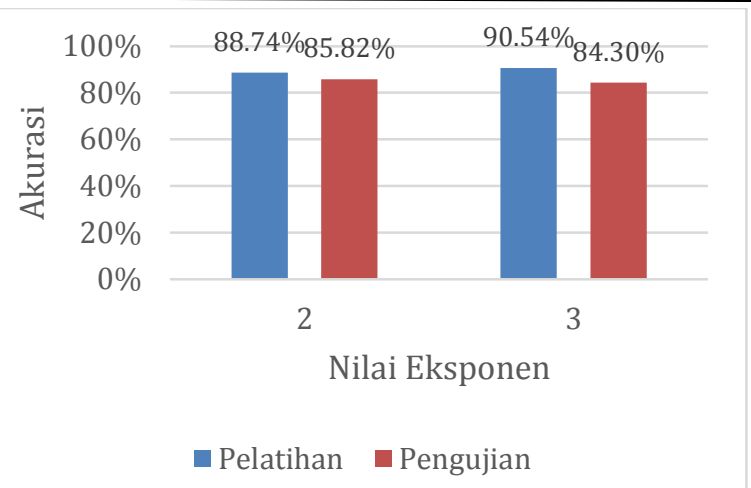

Gambar 7 Grafik akurasi data agresif saham sub sektor

Gambar 11 menunjukkan perbandingan persentase hasil pelatihan dan pengujian pada data agresif saham sub sektor. Persentase hasil pelatihan dan pengujian pada saat nilai eksponen 2 sebesar $88,74 \%$ dan $85,82 \%$, sedangkan saat nilai eksponen 3 persentase hasil pelatihan dan pengujian sebesar $90,54 \%$ dan $84,30 \%$.

Perbedaan nilai eksponen menghasilkan persentase yang berbeda-beda, untuk proses pelatihan apabila nilai eksponen semakin besar maka persentase pelatihan akan semakin tinggi. Persentase pengujian akan semakin rendah apabila nilai eksponen semakin besar. Hal ini menjelaskan hubungan antara nilai eksponen dengan hyperplane, yang mana semakin kecil nilai eksponen maka hyperplane yang dihasilkan akan mendekati bentuk garis linier.

\subsection{Perbandingan Performa}

Hasil dari proses pengujian akan mendapatkan sinyal prediksi beli/jual selama 1 tahun sesuai dengan masing-masing data yang diuji. Proses beli/jual saham selama satu tahun akan menghasilkan keuntungan maupun kerugian. Keuntungan yang didapatkan akan diubah dalam bentuk persentase sehingga didapatkan persentase keuntungan. Kemudian keuntungan dari hasil prediksi akan dibandingkan dengan keuntungan yang didapatkan dari penentuan keputusan beli/jual secara manual.

Data uji yang sudah ditentukan keputusan beli/jual secara manual memiliki keuntungan sebesar $15,91 \%$ atau sebanyak $\mathrm{Rp} 15.911,00$ untuk data non-agresif saham PT Elnusa Tbk. (ELSA), sedangkan keuntungan sebesar 9,83\% atau sebanyak Rp 9.828,00 untuk data agresif saham PT Elnusa Tbk. (ELSA).

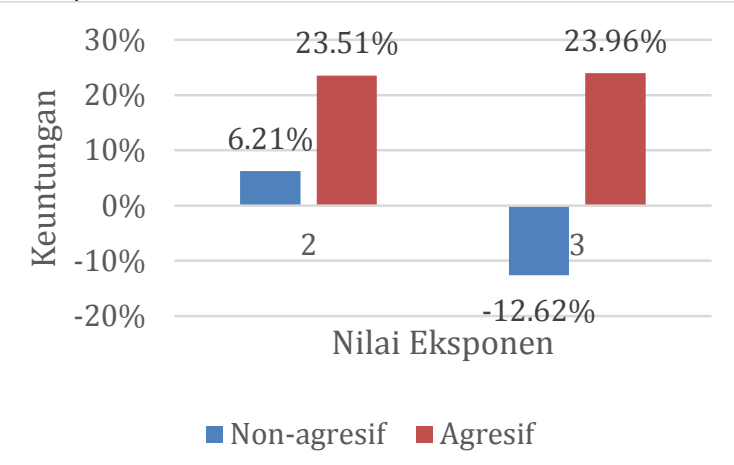

Gambar 8 Grafik keuntungan data saham ELSA

Gambar 12 menunjukkan perbandingan persentase keuntungan yang didapatkan selama 1 tahun dari data non-agresif dan agresif saham PT Elnusa Tbk. (ELSA). Pada perhitungan keuntungan untuk data non-agresif saham PT Elnusa Tbk. (ELSA) didapatkan keuntungan sebesar $6,21 \%$ saat nilai eksponen 2, Sedangkan untuk nilai eksponen 3 mengalami kerugian sebesar $12,62 \%$. Persentase keuntungan yang didapatkan selama 1 tahun dari data agresif saham PT Elnusa Tbk. (ELSA) saat nilai eksponen 2 sebesar 23,51\%. Lalu persentase keuntungan saat nilai eksponen 3 sebesar 23,96\%.

TRANSFORMATIKA Vol. 17, No. 2, January 2020: 179-189 


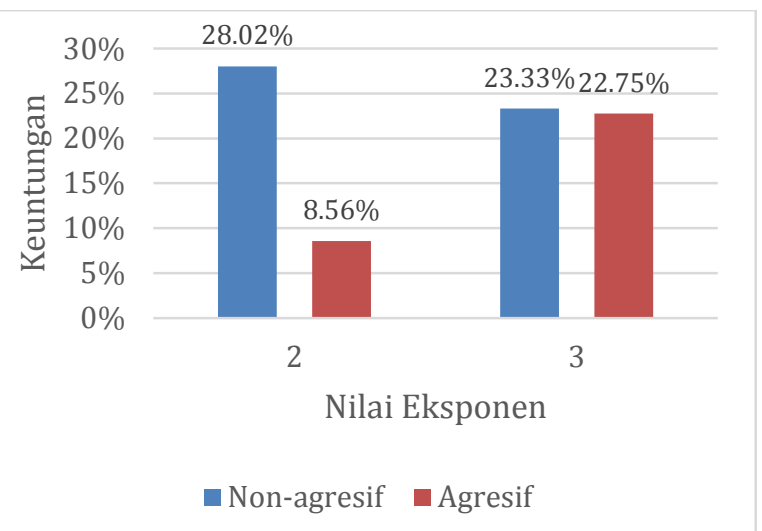

Gambar 9 Grafik keuntungan data saham sub sektor

Gambar 13 menunjukkan perbandingan persentase keuntungan dari data saham sub sektor selama 1 tahun. Pada data non-agresif saham sub sektor saat nilai eksponen 2 mendapatkan keuntungan sebesar $28,02 \%$. Kemudian saat nilai eksponen 3 mendapatkan keuntungan sebesar 30,58\%. Persentase keuntungan yang didapatkan selama 1 tahun dari data agresif saham sub sektor saat nilai eksponen 2 sebesar 8,56\%. Kemudian saat nilai eksponen 3 mendapatkan keuntungan sebesar $22,75 \%$.

\section{Kesimpulan}

Kesimpulan dari penelitian Tugas Akhir ini diantaranya yaitu Indikator Bollinger Bands, Pivot Point, MACD, Stochastic, ADX, dan CCI dapat dikombinasikan untuk menganalisa pergerakan saham. Persentase pengujian tertinggi dengan data saham PT Elnusa Tbk. (ELSA) didapatkan saat menggunakan data non-agresif dengan nilai eksponen 2 yaitu sebesar $92,34 \%$. Persentase pengujian tertinggi dengan data saham sub sektor didapatkan saat menggunakan data non-agresif dengan nilai eksponen 2 yaitu sebesar 91,95\%. Di antara data saham PT Elnusa Tbk. (ELSA) dengan data saham sub sektor, persentase pengujian tertinggi terdapat pada data nonagresif saham PT Elnusa Tbk. (ELSA) dengan nilai eksponen 2 yaitu sebesar 92,34\%. Persentase hasil pelatihan akan semakin besar nilainya ketika nilai eksponen semakin besar pula, namun persentase hasil pengujian akan semakin kecil. Keuntungan tertinggi yang didapatkan pada penelitian ini yaitu sebesar Rp 28.019,00 atau 28,02\%. Model terbaik yang dihasilkan pada penelitian ini adalah data yang dilatih menggunakan data saham non-agresif sub sektor menggunakan nilai eksponen 2, dikarenakan menghasilkan keuntungan tertinggi. Keuntungan yang didapatkan tidak terpengaruh dari hasil persentase pengujian. Keuntungan dari data hasil prediksi yaitu $28,02 \%$ lebih besar dibandingkan dengan keuntungan yang didapatkan dari data aktual yaitu $15,91 \%$, sehingga algoritma SVM dapat membantu untuk memunculkan sinyal keputusan pertama yang lebih baik.

Saran yang dapat diberikan dari penelitian Tugas Akhir ini yaitu, melakukan pengklasifikasian data dengan menggunakan kernel yang berbeda dari algoritma Support Vector Machine (SVM) agar mengetahui kerne/ mana yang dapat memperoleh akurasi terbaik saat proses pelatihan dan pengujian data. Menganalisis data saham menggunakan analisis teknikal membutuhkan analis data yang kompeten dalam bidang trading saham guna menentukan kelas pada data latih dan data uji sehingga menghasilkan kelas yang akurat. Pengembangan aplikasi untuk memprediksi sinyal beli/jual dengan library WEKA dibutuhkan guna mempermudah trader dalam menentukan keputusan beli/jual saham.

\section{References}

[1] May, Ellen. Trading Profit 2. Solo: Ellen May Institute, 2014.

[2] Gupta, Abhineet, dan Baij Nath Kaushik. "Feature Selection from Biological Database for Breast Cancer Prediction and Detection Using Machine Learning Classifier." Journal of Artificial Intelligence, 2018: 57. 
[ 3 ] Vapnik, V., dan C. Cortes. "Support Vector Networks." Machine Learning, 1999: 273.

[ 4 ] Panggabean, Reza Fahlevi. Aplikasi Pendeteksi Sinyal Buy/Sell Saham Bursa Efek Indonesia (BEI) Melalui Indikator Bollinger Bands dan Williams Percent Range. Skripsi S-1, Semarang: Universitas Diponegoro, 2018.

[ 5 ] Pranata, Tegar Widya. Aplikasi Pendeteksi Sinyal Buy/Sell Saham Bursa Efek Indonesia (BEI) Melalui Indikator Moving Average Convergence Divergence (MACD) dan Bollinger Bands. Skripsi S-1, Semarang: Universitas Diponegoro, 2018.

[6] Mutmainah, dan Sri Sulasmiyati. "Analisis Teknikal Indikator Stochastic Oscillator Dalam Menentukan Sinyal Beli dan Sinyal Jual Saham.” Jurnal Administrasi Bisnis, 2017.

[ 7 ] Paul, Sarbajit. "An Empirical Study on Nifty Stocks by applying ADX and Moving Average ." S.S.M. Journal of Science of Humanities, 2016: 89-90.

[ 8 ] Supriadi, Andri. Probabilitas Profit Sinyal Jual dan Sinyal Beli Indikator Teknikal Perdagangan Foreign Exchange Euro Dolar Amerika (EURUSD). Skripsi S-1, Bandar Lampung: Universitas Lampung, 2014.

[9] Octaviani, Pusphita Anna, Yuciana Wilandari, dan Dwi Ispriyanto. "Penerapan Metode Klasifikasi Support Vector Machine (SVM) Pada Data Akreditasi Sekolah Dasar (SD) di Kabupaten Magelang." Jurnal Gaussian. Volume 3, 2014: 811.

[10 ] Pratama, Arif, Randy Cahya Wihandika, dan Dian Eka Ratnawati. "Implementasi Algoritme Support Vector Machine (SVM) untuk Prediksi Ketepatan Waktu Kelulusan Mahasiswa." Jurnal Pengembangan Teknologi Informasi dan IImu Komputer. Volume 2, 2018: 1704. 